Société d'histoire de la révolution de 1848 et des

révolutions du XIXe siècle

Savoirs occultés : du magnétisme à l'hypnose

\title{
William GALLOIS, The Administration of Sickness. Medicine and Ethics in Nineteenth-Century Algeria
}

Basingstoke, Palgrave Macmillan, 2008, 262 p. ISBN : 978-0-23050-043-3. 50 livres sterling

\section{Charlotte Ann Legg}

\section{OpenEdition}

Édition électronique

URL : http://journals.openedition.org/rh19/3900

DOI : $10.4000 /$ rh 19.3900

ISSN : $1777-5329$

Éditeur

La Société de 1848

Édition imprimée

Date de publication : 1 juillet 2009

Pagination : 160-162

ISSN : 1265-1354

\section{Référence électronique}

Charlotte Ann Legg, «William GALLOIS, The Administration of Sickness. Medicine and Ethics in

Nineteenth-Century Algeria », Revue d'histoire du XIXe siècle [En ligne], 38 | 2009, mis en ligne le 04 septembre 2009, consulté le 22 septembre 2020. URL : http://journals.openedition.org/rh19/3900 ; DOI : https://doi.org/10.4000/rh19.3900

Ce document a été généré automatiquement le 22 septembre 2020.

Tous droits réservés 


\section{William GALLOIS, The Administration of Sickness. Medicine and Ethics in Nineteenth-Century Algeria}

Basingstoke, Palgrave Macmillan, 2008, 262 p. ISBN : 978-0-23050-043-3. 50 livres sterling

Charlotte Ann Legg

1 Revendiquant une approche éthique de l'histoire de la médecine, principalement en situation coloniale, William Gallois examine le développement des structures de la médecine française en Algérie, et pose la double question de leur efficacité et de leur moralité. Il cherche ainsi à démontrer que les principes politiques et moraux qui ont guidé l'incomplète mise en place des structures de ce dispositif médical ont émergé immédiatement après la conquête de 1830, et ont persisté tout au long de la période coloniale. Ces idées fondatrices seraient marquées par l'existence d'une imagination colonisatrice dépassant, dans son désir d'assainir le territoire et les populations indigènes, les limites des ressources matérielles disponibles, ainsi que par la symbiose, dans cette œuvre d'assainissement, des impulsions humanistes et "exterminatrices». Montrant l'écart qui sépare les rêves des médecins et des hommes politiques de la réalité de l'offre médicale proposée aux communautés indigènes, William Gallois développe un argument déjà présenté par Yvonne Turin ${ }^{1}$ qui suggère qu'avant 1880 la médecine constituait un véhicule important pour la construction idéologique d'une «mission civilisatrice» et montre l'échec définitif du projet idéologique de «l'impérialisme médical » (p. 29) au cours des dernières années du XIX ${ }^{\mathrm{e}}$ siècle. Pour l'auteur, si des contraintes matérielles (l'instabilité du milieu politique, la législation mal formulée, le manque des moyens) et des tensions structurelles entre médecine militaire, médecine de colonisation et médecine privée ont certes joué, cet échec serait la conséquence d'un raidissement des hiérarchies raciales préexistantes menant progressivement à l'exclusion effective des Arabes musulmans des institutions médicales françaises, tant comme praticiens que comme clients. 
2 Afin de montrer la résonance politique de la médecine comme moyen d'imaginer et de réaliser en même temps la société coloniale, William Gallois met en regard l'analyse des textes des médecins avec les rapports et correspondances des soldats, des fonctionnaires et des hommes politiques. À travers ce mouvement entre l'imaginaire et l'activité coloniale, l'auteur montre bien ce qui lie les courants à la fois humanistes et exterminateurs de la pensée médicale et les conséquences tragiques de cette pensée double. En expliquant comment la neutralité prétendue d'une pensée médicale qui se présentait comme universelle pouvait fournir les prémisses morales à l'extermination de peuples indigènes - qui auraient menacé, aux yeux des colonisateurs, la santé et le progrès de la colonie tout entière-, William Gallois identifie une «culture de l'élimination" (p.100) au cœur de l'affrontement colonial en Algérie, une culture autant perceptible dans une offre médicale défaillante que dans les actions militaires contre les communautés arabes. Dans une série des chapitres situés au cœur du livre, William Gallois examine ce qu'il désigne comme " un programme de génocide » (p. 141) qui aurait encadré les premières campagnes militaires des années 1830, les famines et les crises démographiques de la période 1868-1872, et l'insuffisance de la réponse médicale qui a caractérisé l'ensemble de l'époque coloniale. En posant la question de la légitimation médicale de l'élimination des communautés, l'auteur entend élargir la portée habituelle des études historiques de la médecine.

William Gallois réserve une analyse subtile aux dossiers individuels des six médecins d'origine algérienne qui ont servi comme auxiliaires coloniaux pendant les dernières décennies du XIXe siècle. La correspondance officielle de ces praticiens explique les difficultés qu'ils ont dû affronter pour franchir les frontières raciales de la profession médicale, et leur désillusion face aux promesses manquées de "l'impérialisme médical ». William Gallois situe ces praticiens dans la lignée des critiques éthiques de la colonisation française en Algérie, qui va des premiers opposants à la conquête jusqu'à Frantz Fanon et au FLN, et met en avant leurs idées de perte d'autonomie et "d'identification de la contribution nuisible de l'État colonial à la santé de la nation algérienne»(p.186). De plus en plus repoussés des institutions de la médecine coloniale, ces praticiens auraient donc réinvesti la notion "d'impérialisme médical » pour exprimer leur opposition croissante au régime colonial. Reste que, dans la conception théorique de l'auteur, cette opposition ne peut s'exprimer pleinement que de l'extérieur du pouvoir colonial lui-même, par l'affrontement de deux éthiques médicales différentes. Cependant, on peut imaginer des formes de subversion politique fondées sur l'usage stratégique d'idées empruntées à la médecine coloniale, ou sur l'exploitation des désaccords médicaux ou politiques au sujet de la définition de concepts flous, tels que celui de « race ».

4 Intervention bienvenue dans un champ de recherche toujours en émergence, le livre de William Gallois en reste néanmoins à une conception «superstructurale » de l'empire. Étude engagée, parfois provocatrice, cette exploration des grands axes idéologiques et moraux de la médecine coloniale en Algérie nous invite à examiner de plus près les pratiques et les expériences vécues pour cerner les tensions et fractures à l'intérieur même de la pensée médicale coloniale et d'une société coloniale médicalisée. 


\section{NOTES}

1. Yvonne Turin, Affrontements culturels dans l'Algérie coloniale. Écoles, médecines, religion, 1830-1880, Paris, Maspero, 1971. 